\title{
CORRIGENDUM
}

\section{Legionella jordanis in hematopoietic SCT patients radiographically mimicking invasive mold infection}

\author{
R Meyer, U Rappo, M Glickman, SK Seo, K Sepkowitz, J Eagan and TN Small
}

Bone Marrow Transplantation (2011) 46, 1166; doi:10.1038/bmt.2011.151

Correction to: Bone Marrow Transplantation (2011) 46, 1099 1103; doi:10.1038/bmt.2011.94; published online 16 May 2011.

Since the publication of this article, the authors have noticed Figure 3 appeared incorrect in the online version of their paper.
This error has now been rectified and the correct article appears in this issue. The html and online pdf versions have also been rectified, and now carry the correct paper.

The authors would like to apologize for this error. 